\title{
Efficiency and Unrestricted Gifts in the Guatemalan Nonprofit Sector
}

\author{
Asia Haley Newlin-Blackwell ${ }^{1}$, Harriette Rothwell ${ }^{2}, \&$ Isabela Lyrio \\ ${ }^{1}$ asia@ pionerophilanthropy.com \\ ${ }^{2}$ harriette@pionerophilanthropy.com
}

Key Contributors: Pionero Philanthropy

As the nonprofit sector continues to grow, a shift in funding has occurred, from giving unrestricted gifts to giving primarily restricted donations. This shift places increased pressure on nonprofits to appear efficient and is especially predominant in the international sector. This study aims to understand how this shift in funding has created issues for Pionero Philanthropy's nonprofit partners in the Republic of Guatemala.

After conducting 56 semi-structured interviews with Pionero Philanthropy's nonprofit partners across Guatemala, thematic analysis revealed where funding was most needed: operations, specifically directed towards salaries and staffing. This study shows that by redirecting the focus away from efficiency and toward the promotion of comprehensive donor education, donors will gain more trust in nonprofits and will be more willing to give larger unrestricted gifts to operations. By funding this need, Guatemalan nonprofits will have the opportunity to perform better across Pionero Philanthropy's Five Pillar Evaluation, an evaluation system that measures five best practices supported by nonprofit academic literature (sustainability, impact, transparency, relevance, and a redefined efficiency).

Keywords: philanthropy, nonprofit sector, efficiency, unrestricted gifts

\section{INTRODUCTION}

Pionero Philanthropy (Pionero) is a Florida registered 501(c)3 nonprofit consultancy currently located in the Republic of Guatemala. Its mission is to "support grassroots nonprofits in creating a brighter future for Central American communities by guiding donors on their philanthropic journey, making meaningful and lasting outcomes" (Pionero Philanthropy 2020). In this capacity, Pionero aims to aid in the development of Guatemala by forming partnerships with local noteworthy nonprofit organizations (NPOs) and connecting them with philanthropic donors primarily located in the United States. The organization has developed a database and is currently working on a mapping application of Guatemala's NPO environment. This includes approximately 12,000 NPOs located in the country that are categorized by Pionero partnership status (partner, discontinued, eligible, non-eligible), as well as numerous other variables. NPOs that are eligible for partnerships with Pionero Philanthropy go through the organization's unique methodology and evaluation in order to form stronger, more trusting relationships with donors in the US.

As the nonprofit sector continues to expand, many funders have pushed for increased efficiency, widely represented by the below average ratio of administrative expense to total expense. Due to the increased selectiveness of funders, nonprofits have had to reorganize their management and performance to reduce their operations and increase the programmatic impact of funding. Individual donors often prefer to provide funding restricted to specific programs, and, especially in the context of international aid, they expect to see their gift make a direct impact. As of 2000, this trend was also reflected within the grant context, where grantmaking foundations provided three times more project grants than operating grants (Frumkin \& Kim 2000).

This shift resulted in increased competition for operations and overhead funding. This competition continues to be fueled by the media and nonprofit rating sites, such as Charity Navigator, GuideStar, BBB Wise Giving Alliance, and CharityWatch. These organizations provide publicly 
available evaluations and awards for efficiency as defined by the watchdogs themselves. For example, Charity Navigator scores a nonprofit's administrative expenses on a scale of 0 to 10 . The website explains that by using NPO 990 tax forms to average expenses over a period of three years, the efficiency measure "reflects what percentage of its total budget a charity spends on overhead, administrative staff and associated costs, and organizational meetings" through a simple math equation (Charity Navigator 2019). Administrative expenses under 15 percent receive a top score of 10 , whereas those over 30 percent receive a score of zero.

However, it is believed that this emphasis on efficiency, so narrowly defined, creates an unrealistic picture of nonprofit management and potentially incentivizes ethical violations. When it comes to self-reported 990 tax forms, organizations may feel the need to appear as if they spend less on administration by fabricating the input (Frumkin \& Kim 2000). Such drastic measures are being taken to ensure an appearance of efficiency and thus to secure funding. However, a study by Frumkin and Kim demonstrated that positioning an organization as efficient in this sense does not actually lead to increased donations. This is due to donors placing greater importance on giving to a cause that they personally identify with than one that shows efficiency on their 990 tax forms. As such, one might wonder why there is such emphasis placed on efficiency in our modern society, why a stigma exists against operational expenses, why there are so many restricted gifts, and how this is impacting the nonprofit sector.

To answer these questions, this study examines where funding is most needed in the Guatemalan nonprofit sector. First, an evaluation of interview responses by Pionero nonprofit partners located across Guatemala is presented in order to identify where funding is needed most within their organizations. Second, the findings are compared to the U.S. philanthropic environment, as the majority of philanthropic gifts received in Guatemala originate in the United States. Third, recommendations are provided to address this challenge going forward. By redirecting the focus away from this definition of efficiency and toward the promotion of comprehensive donor education, donors should gain more trust in nonprofits and be more willing to give larger unrestricted gifts to operations. This would enable Guatemalan nonprofits to perform better across Pionero Philanthropy's Five Pillar Evaluation, an evaluation system that measures five best practices supported by nonprofit academic literature (sustainability, impact, transparency, relevance, and a redefined efficiency).

\section{METHODS}

In 2018, Pionero Philanthropy conducted semi-structured interviews with 44 nonprofit partners located in the Republic of Guatemala. These nonprofits were sought out for potential partnership because they each presented a need for increased funding and faced many barriers in building relationships with donors from the US. In an effort to form working relationships and evaluate these organizations, interviews were conducted between the nonprofits and Pionero Philanthropy.

All interviews took place in person at the nonprofit locations. Interview notes were handwritten and later transferred electronically to a database of nonprofits.

Fifty-six organizations were solicited to participate, and 44 of them participated and provided answers with adequate depth and clarity for use in this study. Some interviews were conducted in Spanish and later translated to English. The main interview question concerned funding needs. All nonprofits were asked the question: "where is funding most needed?"

After responses were compiled in Pionero Philanthropy's nonprofit database, thematic analysis was used to divide responses into two major categories: operations and other (composed of programming expenses.) The operations category was then further divided into five separate operational subcategories: salaries and staffing, general operations, capacity building, administration, and consultancy. 


\section{RESULTS}

Guatemalan nonprofit organization partners were asked where funding was most needed, and 25 out of 44 responses, or nearly 57 percent, noted operations. The other 43 percent noted programming expenses; though not an insignificant proportion of responses, this study focuses mainly on operational needs. Of those citing operations, 44 percent reported needing the funding for salaries and staffing, 28 percent reported a need for general operations, 12 percent for capital building, 12 percent for administration, and 4 percent for a consultancy.

\section{Where is funding most needed in the Guatemalan Nonprofit} Sector?

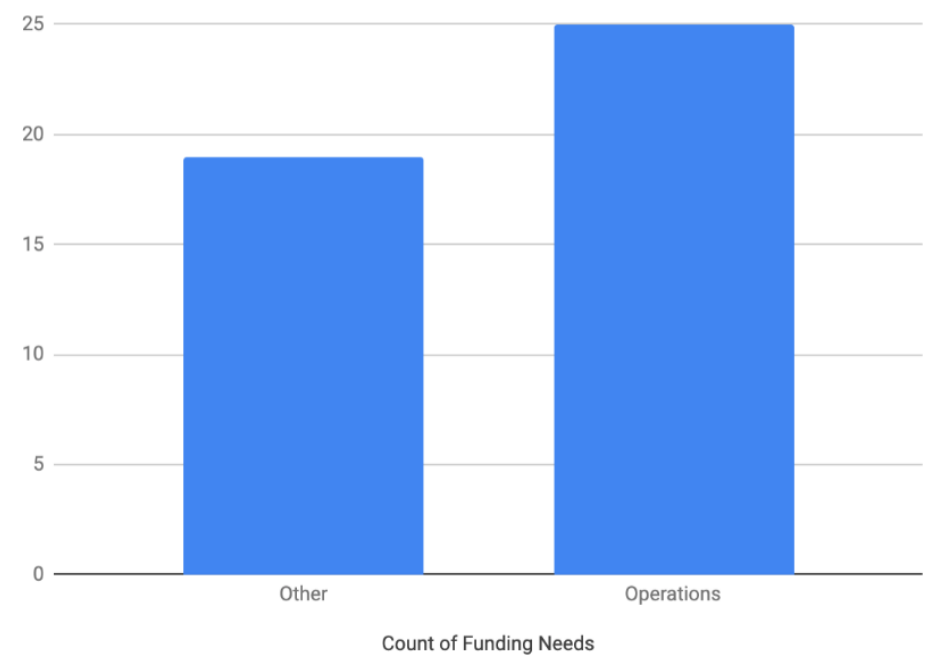

\section{DISCUSSION}

In an interview question about funding needs, nearly 57 percent of nonprofit organizations noted overhead. The hegemonic focus on efficiency in today's society would rate these nonprofits poorly and would view this nonprofit funding need response as a bad thing. However, it cannot be denied that many Guatemalan nonprofits desperately need funds for operations and that they are struggling to meet that need through donations. These operations costs include administration, consultancy, capital building, and general operations; however, salaries and staffing constitute almost half (44\%) of the most requested operational funding.
Where are operational funds most needed in the Guatemalan Nonprofit Sector?

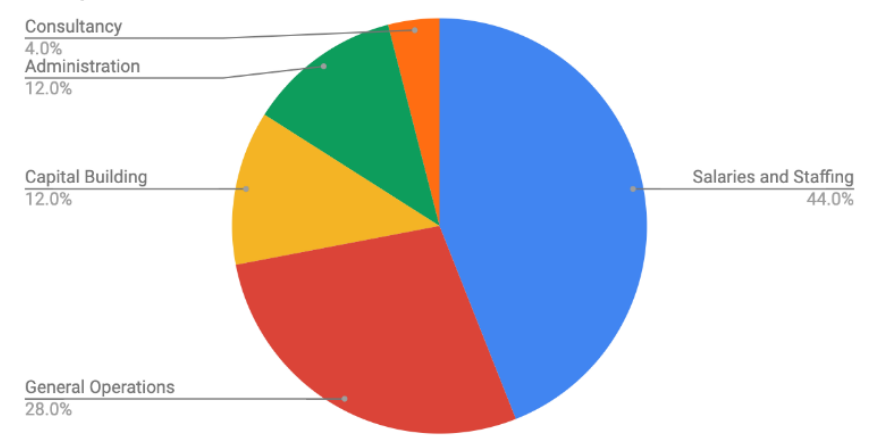

The push for efficiency in nonprofit management brought with it a professionalization of the nonprofit sector. It began the construction and call for expert knowledge, which in turn influenced the rise of salaries in the developmental sphere (Frumkin \& Kim 2000). However, thrown off by the sector's name, the general public holds expectations that nonprofits will be run entirely off of free volunteer labor or by limited staff members earning low salaries. This is despite the fact that the education, skills, and expertise now required to work in nonprofit administration match those of the for-profit sector. The perceived imbalance between nonprofit salary expectations and nonprofit salary realities leads to distrust amongst donors.

Dually fueled by today's emphasis on efficiency, the majority of donors believe that nonprofits are simply wasting money by providing salaries that are perceived to be too high. A 2008 study by Paul C. Light, "How Americans View Charities: A Report on Charitable Confidence," found that only 16 percent of a sample population of 1,001 people had a "great deal" of confidence in charitable organization, 48 percent had a "fair amount" of confidence, 25 percent reported "not too much," and 9 percent reported "none at all." Of the nine percent of respondents that reported "none at all," 88 percent believed that "charitable organizations waste a great deal or fair amount of money," and 76 percent believed that "executives of charitable organizations are paid too much." Of the 25 percent that reported "not too much" confidence, 77 percent believed that "charitable organizations waste a great deal or fair amount of money," and 57 
percent believed that "executives of charitable organizations are paid too much." Even among the population that had a "fair amount" or a "great deal" of confidence in charitable organization, 68 percent and 56 percent, respectively, believed that "charitable organizations waste a great deal or fair amount of money," and 37 percent and 24 percent believed that "executives of charitable organizations are paid too much" (Light 2008). Despite the laws and regulations put forth by the IRS to ensure protection against private inurement in the nonprofit sector (that is, employees may not receive excessive compensation and that funds must be used to advance the organization's mission,) there is still a great deal of mistrust amongst the general population (Hopkins 2017). It is this lack of trust that is causing donors to restrict the use of their gifts.

However, there is an exception to the current trends in donations regarding unrestricted giving. The 2016 U.S. Trust Study of High Net Worth Philanthropy concluded that 73.6 percent of the largest gifts made by high net worth households in 2015 were unrestricted. 29.4 percent of high net worth households actually prefer giving unrestricted gifts, and 50.5 percent have no preference over giving gifts that are restricted or unrestricted. 44.2 percent reported that unrestricted gifts "allow organizations to meet and sustain their missions." 38.8 percent reported that giving unrestricted gifts "places the decisions about funding allocation and budgeting at the organizational level," allowing funding to be used where it is most needed. 29.1 percent believe unrestricted gifts "are critical to the survival of the organizations" and 21.6 percent believe that they "give organizations the ability to build capacity" (Pasic et al. 2016). These statistics beg the sector to question why high net worth donors have such a drastically different view on giving than other donor groups? Why do high net worth donors not experience the same lack of trust as general donors? Why are they not concerned with their gifts being spent on operations? The answer leads back to education.

The U.S. Trust study acknowledges the importance of advocating for education about the needs of nonprofits. The study refers to the nonprofit knowledge that high net worth donors have and found that as knowledge about charitable giving increases, so does the average gift amount. High net worth donors who considered themselves at the novice level of charitable knowledge donated an average of $\$ 3,303$. Donors at the knowledgeable level donated $\$ 8,285$, and high net worth donors at the expert level of charitable knowledge donated an average of $\$ 14,322$ (Pasic et al. 2016). Is expert knowledge a causal factor in the giving of unrestricted gifts by high net worth donors?

Though the data to show a causal relationship is not yet available, the implications of such a relationship are substantial. If we assume this causal relationship and apply this finding to the general donor population, perhaps the simplest solution to increasing unrestricted gifts and gift size in Guatemala is through charitable education. Increased knowledge about where nonprofits most need funding and the nonprofit sector in general would build trust with potential donors. This education holds the potential power to grant donors the understanding and confidence to give large unrestricted gifts that could be used to cover the need for operational funding in the Guatemalan nonprofit environment.

For this reason, Pionero has developed a new system of NPO evaluation based on a fivepillar approach. This not only evaluates an NPO on efficiency, redefined by the Organization of Economic Co-Operation and Development (OECD) as "a measure of how economic resources/inputs (funds, expertise, time, equipment, etc.) are converted into results" (OECD 2019), but also refocuses some of the attention on NPO relevance, sustainability, impact, and transparency. This new comprehensive system of evaluation provides donors culturally contextualized information and education about Pionero's partner NPOs in Guatemala. By placing importance on and educating donors about management objectives and best practices in addition to efficiency, donors will realize the importance of unrestricted gifts. Without this funding, NPOs cannot succeed in the other four pillars. An investment in operations, including 
salaries, is an investment in the overall quality of the NPO.

\section{CONCLUSION}

Donor education and raising awareness of the importance of funding operations is imperative for the Guatemalan nonprofit sector to continue to grow and better serve the wide array of community needs in the country. With more unrestricted gifts to cover overhead and operations, including salaries and staffing, nonprofits can more easily strengthen their programs and work towards being truly sustainable, impactful, transparent, relevant, and efficient. It is past time for the philanthropy world to accept that overhead and operations are the foundation for nonprofit success.

Pionero Philanthropy is a philanthropy consultancy whose mission is to support grassroots nonprofits in Guatemala by guiding donors on their philanthropic journey. Pionero is committed to providing education to nonprofits in Guatemala and the donors who are seeking to support them. Pionero invests considerable time getting to know its nonprofit partners through on-the-ground presence and regular communication. Thanks to these relationships, Pionero is uniquely positioned to guide donors on nonprofit funding needs and the importance of unrestricted funding. At present, Pionero is carrying out such education on an individual level throughout its consultations; however, it is undeniable that a larger educational campaign is needed in order to reach the wider population. Pionero believes that through educational efforts, donors can come to appreciate the importance of and feel pride in supporting nonprofit operations.

\section{ACKNOWLEDGEMENTS}

We would like to formally acknowledge Pionero Philanthropy and the Pionero team whose extensive network and database of nonprofit organizations in Guatemala made this study possible. Specials thanks to Emma Burke, Rodrigo Fresse, and Kelly Leach for their assistance in reviewing this article.

\section{LITERATURE CITED}

Evaluation of Development Programmes. Organisation for Economic Co-operation and Development (OECD). http://www.oecd.org/dac/evaluation/daccriteriaforevalua tingdevelopmentassistance.html

Frumkin, P., Kim, M.T. 2000. Strategic Positioning and the Financing of Nonprofit Organizations: Is Efficiency Rewarded in the Contributions Marketplace? Hauser Center for Nonprofit Org. Working Paper No. 2. Harvard University, The Hauser Center for Nonprofit Organization and The Kennedy School of Government.

Hopkins, Bruce R. 2017. Starting and Managing a Nonprofit Organization: A Legal Guide. John Wiley \& Sons, New York, New York.

Light, P.C. 2008. How American View Charities: A Report on Charitable Confidence. Report no. 15. Governance Studies, The Brookings Institution, Washington, D.C.: Brookings.

Pasic, A., Rooney, P., Osili, U., Clark, C., St. Claire, M., Bergdoll, J., Davis, A., Kalugyer, Card, M., Chaillou, J., Costello, C., Ehrenfeld, J., Howell, G., Laufman, M., Maclay, N., Amato-Milligan, D., Ratcliffe, D., Slugg, R. 2016. The 2016 U.S. Trust Study of High Net Worth Philanthropy: Charitable Practices and Preferences of Wealthy Households. Lilly Family School of Philanthropy, IUPUI \& U.S. Trust, Bank of America, Indianapolis, Indiana.

Your Guide to Intelligent Giving. Charity Navigator. https://www.charitynavigator.org/ 